\title{
Admission platelet count and indices as predictors of outcome in children with severe Sepsis: a prospective hospital-based study
}

Samira Z. Sayed ${ }^{1}$, Mohamed M. Mahmoud ${ }^{1}$, Hend M. Moness ${ }^{2}$ and Suzan O. Mousa ${ }^{1 *}$ (1)

\begin{abstract}
Background: Sepsis is still one of the main causes of infants and children mortality especially in developing, economically challenged countries with limited resources. Our objective in this study was to determine, the prognostic value of platelet count, mean platelet volume (MPV), platelet distribution width (PDW) and plateletcrit (PCT) in critically ill infants and children with severe sepsis, as they are readily available biomarkers, that can guide clinicians during managing of severe sepsis.
\end{abstract}

Methods: Sixty children were included; they were diagnosed with severe sepsis according to the international pediatric sepsis consensus conference criteria. At admission to Pediatric intensive care unit, complete blood count with platelet count and parameters (MPV, PDW and PCT) and C-reactive protein (CRP) level were determined for all children. Also, assessment of the Pediatric Risk of Mortality (PRISM III) score was done to all. These children were followed up till discharge from hospital or death. Accordingly, they were grouped into: (1) Survivor group: included 41 children. (2) Non-survivor group: included 19 children.

Results: Platelet count and PCT were significantly lower $(p<0.001)$ and MPV was significantly higher in nonsurvivor than survivors $(p=0.004)$. MPV/PLT, MPV/PCT, PDW/PLT, PDW/PCT ratios were found to be significantly higher in the non-survivors than survivor ( $p<0.001$ in all). PCT with sensitivity $=94.74 \%$, was the most sensitive platelet parameter for prediction of death, while MPV/PCT was the most sensitive ratio (sensitivity $=94.7 \%$ ).

Conclusion: Thrombocytopenia, platelet indices and their ratios, especially plateletcrit and MPV/PCT, are readily available, sensitive, prognostic markers, that can identify the severe sepsis patients with poorest outcome.

Keywords: Severe sepsis, Platelet indices, Thrombocytopenia, Mean platelet volume, Platletcrit, platelet ratios

\footnotetext{
* Correspondence: suzanmousa@mu.edu.eg

'Pediatric Department, Children's University hospital, Faculty of Medicine, Minia University, El-Minya, Egypt

Full list of author information is available at the end of the article
}

(c) The Author(s). 2020 Open Access This article is licensed under a Creative Commons Attribution 4.0 International License, which permits use, sharing, adaptation, distribution and reproduction in any medium or format, as long as you give appropriate credit to the original author(s) and the source, provide a link to the Creative Commons licence, and indicate if changes were made. The images or other third party material in this article are included in the article's Creative Commons licence, unless indicated otherwise in a credit line to the material. If material is not included in the article's Creative Commons licence and your intended use is not permitted by statutory regulation or exceeds the permitted use, you will need to obtain permission directly from the copyright holder. To view a copy of this licence, visit http://creativecommons.org/licenses/by/4.0/. The Creative Commons Public Domain Dedication waiver (http://creativecommons.org/publicdomain/zero/1.0/) applies to the data made available in this article, unless otherwise stated in a credit line to the data. 


\section{Background}

Sepsis is a major childhood disease both in terms of frequency and severity, and severe sepsis is still considered the main cause of death from infection in childhood. The prevalence of severe sepsis and septic shock among hospitalized children ranges from 1 to $26 \%$. Mortality is high, ranging from $5 \%$ in developed countries reaching up to $35 \%$ in developing countries [1].

Although sepsis is considered a worldwide public health problem, it is still not tracked in the Global Burden of Disease report published by the WHO and World Bank [2], which is one of the most important sources of information for health policies decisionmaking in the world [3].

The absence of a well-established sepsis definition is a major obstacle to sepsis epidemiology in children. So, the third sepsis consensus conference (Sepsis-3) in 2016 published updated definitions for sepsis and septic shock that reflect the evolving understanding of sepsis pathobiology. Sepsis was defined as a 'dysregulated host-response' to infection leading to 'life-threatening organ dysfunction'. Importantly, the foundation for this definition was no longer inflammation alone but a lack of immune homeostasis [4].

Unfortunately, definitions frequently provide limited value clinically; thus, 'Sepsis-3' recommends new clinical criteria for the rapid recognition of infected patients likely to suffer poor outcomes (ICU admission, prolonged length of stay, increased mortality) characteristic of sepsis, rather than uncomplicated infections [5]. Many studies performed in both developing and developed countries have shown that mortality from sepsis is high and is associated with delayed diagnosis, late treatment, and nonadherence to the treatment guidelines. Reducing mortality from pediatric sepsis is a worldwide challenge [1].

In the meantime, there are accumulating evidence about the important role of platelets in the inflammatory process, microbial host defense, wound healing, angiogenesis, and remodeling in addition to their contribution to hemostasis and thrombosis [6]. Some proteins released from platelet granules influence vascular wall and immune cell function [6-9], other proteins are microbicidal and antibacterial [8]. Other studies demonstrated the important role platelet play in synthesis and release of vascular endothelial growth factors that is involved in tumor angiogenesis in addition to inflammation in tumor pathogenesis [10].

In recent years, the number of studies suggesting that the platelet and their indices can be used as inflammatory markers in cancer cases in addition to cardiovascular, cerebrovascular, inflammatory and thromboembolic diseases is increasing by the time [11].

In this study, our objective was to determine the prognostic value of thrombocytopenia and platelet indices (MPV, PDW and PCT), in critically ill infants and children with severe sepsis. As they are readily available biomarkers, most clinicians can make good use of, especially in developing countries where most cases of sepsis are.

\section{Subjects and methods Subjects}

This cross-sectional hospital-based study was conducted on infants and children, who were admitted to PICU of Minia University Children and Maternity Hospital. The study was conducted during the period from July 2018 till January 2019.

We included in this study all patients who were diagnosed with severe sepsis according to the international pediatric sepsis consensus conference, which included the following criteria: - Sepsis plus one of the following: cardiovascular organ dysfunction or acute respiratory distress syndrome or two or more other organ dysfunctions [12]. We excluded from our study patients admitted to pediatric intensive care unit (PICU) with causes other than severe sepsis e.g. intracranial hemorrhage, encephalopathy, hematological malignancy or DIC directly related to a malignant disorder. We also excluded patients whom parents refused to participate in the study.

\section{Sample size calculation}

Sample was calculated to be 51 by sample size calculation GPower program at power of $80 \%$ and significance level less than 0.05 . In a similar previous study by Golwala et al. 2016 [13], they calculated a sample size of 34 (17 non-survivors and 17 survivors) for a study power of $80 \%$ at the $5 \%$ level of confidence. Their prediction was based on results of a canine model [14].

All studied patients' data was collected prospectively. Clinical characteristics and laboratory data collected during the first $24 \mathrm{~h}$ of hospital admission were used to determine The Pediatric Risk of Mortality III score (PRISM III score) [15]. Data was collected by the attending PICU resident and verified by one of our study team. PRISM score is used for prediction of mortality in pediatric patients. Recently, the physiologic status as measured with PRISM variables and their ranges could be used to simultaneously estimate morbidity and mortality risk [16]. The included subjects were followed up till discharge from hospital or death. Accordingly, they were grouped into: (1) Survivor group: children in this group were discharged from hospital after surviving severe sepsis attack. (2) Non-survivor group: this group included patients who expired during the course of severe sepsis.

\section{Methods}

Blood samples were drawn from the patients upon admission to the PICU under complete aseptic condition for the following workup: arterial blood gases, random 
blood glucose, complete blood count, C-reactive protein (CRP), serum electrolytes, liver function tests, kidney function tests, prothrombin time, partial thromboplastin time, and blood culture. Cerebro-spinal fluid (CSF) culture and urine culture were only done when clinically indicated complete blood count $(\mathrm{CBC})$ including platelet count and indices was done by fully automated cell counter Sysmex KX-21 N \{TAO Medical Incorporation, Japan). CRP is widely used as a traditional prognostic marker for sepsis. It was assayed by NycoCard Reader II (Axis-Shield PoC AS, Oslo, Norway). CRP levels $<6 \mathrm{mg} /$ dl were considered normal. Routine chemistry tests (blood glucose, renal function and serum electrolytes) were performed using fully automated chemistry analyzer Konelab 60i (Thermo Scientific, Finland). Prothrombin time (PT) and activated partial thromboplastin time (aPTT) were determined by using Fully automated coagulometer STAGO (Diagnostic STAGO - France). Blood samples for ABG were collected in heparin tubes and were determined by ABL90 FLEX blood gas analyzer (Radiometer Medical Apps, Denmark).

ABG, renal function (serum creatinine and blood urea nitrogen (BUN)), PT, aPTT, serum potassium and serum glucose level were used in calculation of PRISM III score.

PRISM score and CRP were determined for all patients to compare platelet count and indices with them.

Any additional laboratory or radiological imaging (chest $\mathrm{x}$-ray, brain computed tomography (CT)) were ordered on case-by-case basis.

\section{Statistical analysis}

The collected data were coded, tabulated, and statistically analyzed using SPSS (Statistical Package for Social Sciences) software version 25. Descriptive statistics were done for parametric quantitative data by mean \pm standard deviation, and for non-parametric quantitative data by median and interquartile range (IQR), while they were done for categorical data by frequency and percentage. Normality of distribution of the data was tested by Kolmogorov Smirnov test. Analyses were done for nonparametric quantitative data using Mann Whitney test between the two groups. Correlations between PRISM score with CRP and other platelets parameters were done using Pearson's correlation coefficient.

ROC (Receiver Operating characteristic) curve analysis of PRISM score, CRP and platelet parameters were done to determine Area Under Curve, optimal cutoff point, sensitivity, specificity, positive predictive value (PPV), negative predictive value (NPV) and accuracy for prediction of death in patient with sepsis. Using the cutoff values from ROC curves analyses, the odds ratio with 95\% confidence interval was calculated using logistic regression analyses. The level of significance was taken at $p<0.05$.

\section{Results}

During the study period, seventy-four infants and children were initially diagnosed as having severe sepsis upon admission to PICU, but only 60 patients were included in this study. As, fourteen patients were excluded: parents of six children refused to participate in the study and eight patients were excluded by the exclusion criteria (Fig. 1).

The sixty children included were 35 (58.3\%) males and 25 (41.7\%) females, with a mean age of $11.6 \pm 7.5$ months. Table 1 shows clinical, radiological, PRISM score and blood culture results of the included patients.

We followed-up the patients till they were discharged from the hospital or died by complications of severe sepsis. Forty-one patients were discharged from the PICU. They were 24 (58.5\%) males and 17 (41.5\%) females with

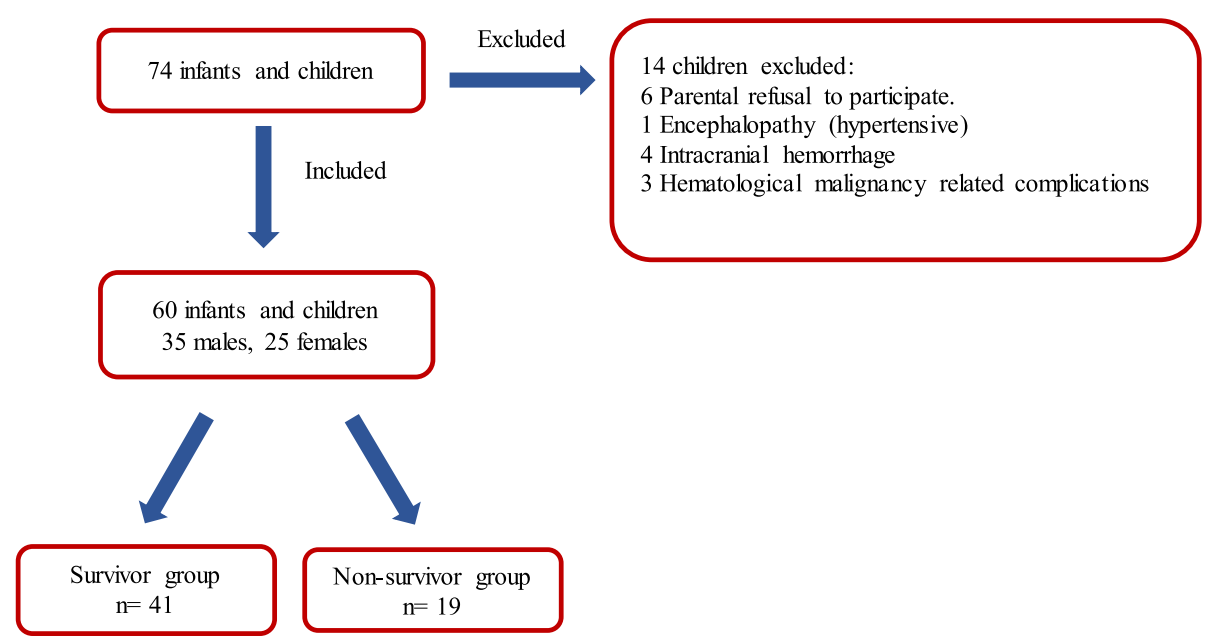

Fig. 1 Flowchart of the enrollment of severe sepsis patients 
Table 1 Clinical, radiological, PRISM score and blood culture organism of the studied patients

\begin{tabular}{|c|c|c|}
\hline & & $\boldsymbol{n}=60$ \\
\hline HR (beat /min) & Mean $\pm S D$ & $162.5 \pm 16.3$ \\
\hline $\mathbf{R R}$ (cycle/min) & Mean $\pm S D$ & $54 \pm 15.9$ \\
\hline \multirow[t]{2}{*}{ BP $(\mathrm{mm} \mathrm{Hg})$} & Normal n (\%) & $11(18.3 \%)$ \\
\hline & Hypotension n (\%) & 49 (81.7\%) \\
\hline \multirow[t]{2}{*}{ Hepatomegaly } & No n (\%) & $15(25 \%)$ \\
\hline & Yes n (\%) & $45(75 \%)$ \\
\hline \multirow[t]{2}{*}{ Chest finding } & No n (\%) & $22(36.7 \%)$ \\
\hline & Yes n (\%) & $38(63.3 \%)$ \\
\hline \multirow[t]{3}{*}{ CXR } & Normal n (\%) & $22(36.7 \%)$ \\
\hline & Pneumonia n (\%) & $37(61.7 \%)$ \\
\hline & Empyema n (\%) & $1(1.6 \%)$ \\
\hline GCS & Mean $\pm S D$ & $8.9 \pm 2.3$ \\
\hline \multirow[t]{3}{*}{ Ventilatory support } & None n (\%) & $11(18.3 \%)$ \\
\hline & Non-invasive n (\%) & $22(36.7 \%)$ \\
\hline & Invasive n (\%) & $27(45 \%)$ \\
\hline \multirow[t]{2}{*}{ (+ve) inotropic support } & No n (\%) & $33(55 \%)$ \\
\hline & Yes n (\%) & $27(45 \%)$ \\
\hline PRISM score & Median / (IQR) & $17 /(10-29)$ \\
\hline \multirow[t]{7}{*}{ Blood culture organism } & Staphylococcus aureus n (\%) & $8(13.33 \%)$ \\
\hline & Klebsiella n (\%) & $13(21.67 \%)$ \\
\hline & Streptococcus pneumoniae n (\%) & $15(25 \%)$ \\
\hline & Escherichia coli n (\%) & $10(16.67 \%)$ \\
\hline & Pseudomonas aeruginosa n (\%) & $4(6.67 \%)$ \\
\hline & Entrobacter n (\%) & $7(11.67 \%)$ \\
\hline & No growth n (\%) & $3(5 \%)$ \\
\hline
\end{tabular}

$H R$ heart rate, $R R$ respiratory rate, $B P$ blood pressure, $C X R$ chest $\mathrm{x}$-ray, GCS Glascow coma scale, PRISM Pediatric risk of mortality score a median/ (IQR) age of $11 /(4-15)$ months. While 19 patients did not survive and died from complications of severe sepsis. They were 11 (57.9\%) males and 8 (42.1\%) females with a median/ (IQR) age of 12/ (2-15) months. Age and sex differences between the two studied groups showed statistical insignificance, as $p>0.05$.

We compared the PRISM score, CRP, platelet count and platelet indices of the survivor versus the non-survivor. The PRISM score and CRP level were significantly higher in non-survivor children than those who survived, as $p<$ 0.001, with odds ratio of 2.1 (95\% CI: 1.1-2.9) for PRISM score and 1.01 (95\% CI: 1.008-1.03) for CRP. While, platelet count and plateletcrit (PCT) were significantly lower in non-survivor than survivors, as $p<0.001$ in both. Their odds ratios were 0.989 (95\% CI: 0.982-0.996) and 0.1 (95\% CI: $0.1-0.15)$ respectively. Meanwhile, the non-survivors had significantly larger mean platelet volume (MPV) than the survivors, as $p=0.004$ (Table 2). MPV odds ratio was 1.9 (95\% CI: 1.005-2.4).

When we calculated platelet indices ratios, MPV/PLT, MPV/PCT, PDW/PLT, PDW/PCT, we found them to be significantly higher in the non-survivor group than the survivor group, as $p<0.001$ in all (Table 3 ). Their odds ratios are presented in Table 3 .

When we correlated the studied markers with PRISM score, PRISM score had significant negative association with both platelet count $(r=-0.420, p=0.001)$ and plateletcrit $(r=-0.442, p=0.001)$. And, it had a significant positive association with CRP level $(r=0.497, p=0.001)$ (Table 4).

Multivariate analysis was done to determine the odds ratios for platelet count, platelet indices and CRP after controlling for PRISM score, the decrease in PCT was the only risk factor reaching statistical significance, as its

Table 2 PRISM score, CRP, platelet count and parameters of the children with severe sepsis according to their outcome

\begin{tabular}{|c|c|c|c|c|}
\hline \multirow[t]{2}{*}{ Variable } & \multirow{2}{*}{$\begin{array}{l}\text { Survivors } \\
\boldsymbol{n}=41\end{array}$} & \multirow{2}{*}{$\begin{array}{l}\text { Non-survivors } \\
\boldsymbol{n}=19\end{array}$} & \multirow[t]{2}{*}{$p$} & \multirow{2}{*}{$\begin{array}{l}\text { Odds ratio } \\
(95 \% \mathrm{Cl})\end{array}$} \\
\hline & & & & \\
\hline $\begin{array}{l}\text { PRISM } \\
\text { Median / (IQR) }\end{array}$ & $11 /(10-15.5)$ & $26 /(24-40)$ & $<0.001 *$ & $2.1(1.1-2.9)$ \\
\hline $\begin{array}{l}\text { CRP }(\mathrm{mg} / \mathrm{dl}) \\
\text { Median / (IQR) }\end{array}$ & 96/ (48-96) & 192/ (96-192) & $<0.001 *$ & $1.01(1.008-1.03)$ \\
\hline $\begin{array}{l}\text { PLT }\left(10^{3} / \mathrm{ml}\right) \\
\text { Median / (IQR) }\end{array}$ & $265 /(115.5-381.5)$ & 73/ (43-104) & $<0.001^{*}$ & $0.989(0.982-0.996)$ \\
\hline $\begin{array}{l}\text { MPV (fl) } \\
\text { Median / (IQR) }\end{array}$ & $7.9 /(7.3-9.5)$ & $9.3 /(8.8-10.7)$ & $0.004^{*}$ & $1.9(1.005-2.4)$ \\
\hline $\begin{array}{l}\text { PDW (\%) } \\
\text { Median / (IQR) }\end{array}$ & 14.9/ (13.9-17.3) & $15.9 /(13.5-17.7)$ & 0.830 & $0.95(0.83-1.08)$ \\
\hline $\begin{array}{l}\text { РCT (\%) } \\
\text { Median / (IQR) }\end{array}$ & $0.22 /(0.18-0.28)$ & $0.09 /(0.07-0.16)$ & $<0.001^{*}$ & $0.1(0.1-0.15)$ \\
\hline
\end{tabular}

PRISM pediatric risk of mortality score, CRP C-reactive protein, $P L T$ platelet count, MPV mean platelet volume, $P D W$ platelet distribution width, $P C T$ plateletcrit, $C I$ confidence interval

Mann Whitney test for non-parametric quantitative data (expressed as median) between the two groups

*Significant difference at $p$ value $<0.05$ 
Table 3 Ratios of platelet indices of the children with severe sepsis according to their outcome

\begin{tabular}{|c|c|c|c|c|}
\hline \multirow[t]{2}{*}{ Variable } & \multirow{2}{*}{$\begin{array}{l}\text { Survivors } \\
\boldsymbol{n}=41\end{array}$} & \multirow{2}{*}{$\begin{array}{l}\text { Non-survivors } \\
\boldsymbol{n}=19\end{array}$} & \multirow[t]{2}{*}{$p$} & \multirow{2}{*}{$\begin{array}{l}\text { Odds ratio } \\
(95 \% \mathrm{Cl})\end{array}$} \\
\hline & & & & \\
\hline $\begin{array}{l}\text { MPV/PLT } \\
\text { Median / (IQR) }\end{array}$ & $0.03 /(0.019-0.08)$ & $0.15 /(0.08-0.25)$ & $<0.001 *$ & $1.01(1.004-1.02)$ \\
\hline $\begin{array}{l}\text { MPV/PCT } \\
\text { (Median / (IQR) }\end{array}$ & $36.25 /(29.2-49.5)$ & $107.78 /(57.5-152.85)$ & $<0.001^{*}$ & $3.83(1.14-7.73)$ \\
\hline $\begin{array}{l}\text { PDW/PLT } \\
\text { Median / (IQR) }\end{array}$ & $0.05 /(0.04-0.15)$ & $0.23 /(0.14-0.39)$ & $<0.001^{*}$ & $1.007(1.001-1.01)$ \\
\hline $\begin{array}{l}\text { PDW/PCT } \\
\text { Median / (IQR) }\end{array}$ & $67.78 /(53.1-91.11)$ & 186.25/ (99.29-260) & $<0.001 *$ & $2.97(1.05-5.46)$ \\
\hline
\end{tabular}

PLT platelet count, MPV mean platelet volume, PDW platelet distribution width, $P C T$ plateletcrit, $C l$ confidence interval

Mann Whitney test for non-parametric quantitative data (expressed as median) between the two groups

"Significant difference at $p$ value $<0.05$

odds ratio was 0.101 (95\% CI: $0.1-0.15)$ with $p=0.02$ (Table 5).

ROC curve analysis of PRISM score, CRP, platelet count and indices for prediction of death in patients with severe sepsis, showed that PCT was the platelet parameter showing the largest area under the curve (AUC of 0.888 ), with a sensitivity of $94.74 \%$ and a specificity of $78.05 \%$ at a cut-off of $\leq 0.17 \%$. The decrease in platelet count had the same sensitivity as PRISM score (sensitivity $=89.47 \%$ ), taking the second place after plateletcrit regarding sensitivity of predicting death. While MPV, at cutoff point $\geq 8.7 \mathrm{fl}$, was the second most specific marker after PRISM score (specificity $=86.29 \%$ ). MPV in this study was the least sensitive platelet parameter (sensitivity $=78.95 \%$ ), but still more sensitive than CRP (sensitivity $=57.89 \%$ ) (Table 6, Fig. 2). While ROC curve analysis of platelet indices ratios revealed that MPV/PCT had the largest area under the curve (AUC of 0.882 ), with a sensitivity of $94.7 \%$ and a specificity of $78 \%$ at a cutoff value of $\geq 49.8$ (Table 7, Fig. 3 ).

\section{Discussion}

In this study, on comparing children with severe sepsis according to their outcome, the non-survivors had higher PRISM score than patients who survived. This

Table 4 Correlations of PRISM score with CRP, platelet count and parameters

\begin{tabular}{lll}
\hline Variable & PRISM & \\
\cline { 2 - 3 } & $\mathrm{r}$ & $\mathrm{p}$ \\
\hline PLT & $\mathbf{- 0 . 4 2 0}$ & $<\mathbf{0 . 0 0 1 *}$ \\
MPV & 0.047 & 0.722 \\
PDW & -0.040 & 0.764 \\
PCT & $-\mathbf{0 . 4 4 2}$ & $<\mathbf{0 . 0 0 1 *}$ \\
CRP & $\mathbf{0 . 4 9 7}$ & $<\mathbf{0 . 0 0 1 *}$
\end{tabular}

PRISM pediatric risk of mortality score, CRP C-reactive protein, PLT platelet count, MPV mean platelet volume, PDW platelet distribution width, PCT plateletcrit

Pearson's correlation coefficient

"Significant level at $p$ value $<0.05$ was in accordance with many studies who found PRISM score to be higher in non survivors [17-19]. Pollack et al., in 2015 stated that the increase in PRISM score is significantly associated with increase in morbidity and mortality and could estimate morbidity and mortality risk [16]. Non-survivors had also higher CRP levels than survivors. It is well known that CRP is an acute phase reactant synthesized in liver in response to infection or inflammation and its serum concentration can increase up to 1000 -fold during acute inflammatory events and correlated well with severity of infection [20]. Moreover, many studies observed that CRP concentrations at ICU admission were associated with organ dysfunction, increased ICU length of stay, and higher mortality [21].

Regarding platelet count and indices, platelet count and PCT were significantly lower in non-survivor than survivors. This was in accordance with Venkata et al., [22], who found that thrombocytopenia carries an independent risk for mortality in ICU patients and is a negative prognostic indicator for adverse clinical outcomes in ICU patients [22]. Also, a recent study stated that thrombocytopenic children at the time of admission have more likelihood of mortality than non-thrombocytopenic children in intensive care units [23]. Gao et al., [24] found that PCT was correlated to platelet count with similar clinical implication, and they found markedly decreased PCT in patients who expired.

Table 5 Multivariate analysis of platelet count, platelet indices and CRP after controlling for PRISM score

\begin{tabular}{lllll}
\hline Variable & \multirow{2}{*}{$\begin{array}{l}\text { Odds } \\
\text { ratio }\end{array}$} & \multicolumn{2}{l}{$95 \% \mathrm{Cl}$ for OR } & $\mathrm{p}$ \\
\cline { 3 - 4 } & & Lower & Upper & \\
\hline PLT & 0.995 & 0.98 & 1.004 & 0.08 \\
MPV & 1.405 & 0.80 & 2.4 & 0.2 \\
PDW & 0.631 & 0.39 & 1.01 & 0.6 \\
PCT & 0.101 & 0.1 & 0.15 & $0.02^{*}$ \\
CRP & 1.012 & 0.99 & 1.02 & 0.17 \\
\hline
\end{tabular}

PLT platelet count, MPV mean platelet volume, PDW platelet distribution width $P C T$ plateletcrit, $C R P$ C-reactive protein, $C l$ confidence interval, $O R$ odds ratio "Significant level at $p$ value $<0.05$ 
Table 6 Predictive values of PRISM score, CRP, platelet count and indices for mortality

\begin{tabular}{|c|c|c|c|c|c|}
\hline Variable & Optimal cutoff & AUC & Sensitivity (\%) & Specificity (\%) & Accuracy $(\%)$ \\
\hline PRISM & $\geq 20$ & 0.892 & 89.47 & 87.8 & 88.3 \\
\hline CRP (mg/dl) & $\geq 96$ & 0.701 & 57.89 & 85.37 & 70.2 \\
\hline Platelets $\left(10^{3} / \mathrm{ml}\right)$ & $\leq 117$ & 0.831 & 89.47 & 75.61 & 80 \\
\hline MPV (fl) & $\geq 8.7$ & 0.731 & 78.95 & 86.29 & 71.7 \\
\hline PCT (\%) & $\leq 0.17$ & 0.888 & 94.74 & 78.05 & 83.3 \\
\hline
\end{tabular}

PRISM pediatric risk of mortality score, CRP C-reactive protein, $P L T$ platelet count, MPV mean platelet volume, $P C T$ plateletcrit, $A U C$ Area under curve

The low platelet count in non-survivors may be attributed to the depletion of coagulation factors and platelet consumption during the septic process and the low PCT in the non-survivors may be imputed to that PCT is influenced by number and size of platelets and has a positive relationship with platelet count [24].

Meanwhile, the non-survivors had significantly larger MPV than the survivors. This situation may be caused by production of many cytokines, endothelial damage, and bone marrow suppression in septic patients [25]. A study by Margetic, in 2012 showed that MPV acts as an acute phase reactant in different inflammatory conditions, they stated that high MPV levels were associated with high-grade inflammation owing to the presence of large platelets in circulation [6]. Two prospective studies demonstrated significant correlations between increased
MPV and short-term mortality [26, 27]. Also, a study by Tajarernmuang et al. in 2016, on adults, revealed that the gradual increase in MPV after a few days of admission was associated with increased hospital mortality [28]. An elevation of MPV suggests that the infection is invasive and uncontrolled and is related to the severity of the disease, a finding which was verified in our study, and may be useful as an assessment tool for outcome prognosis.

Furthermore, a study by Sezgi et al., in 2015 showed that in patients with sepsis the MPV level was increasing during the course of the disease in non-survivors, while it was found to be decreasing in the surviving group [29].

In our study PDW increased in non-survivors than survivors, but this increase did not reach statistical significance. The PDW is increased when there is an increase in

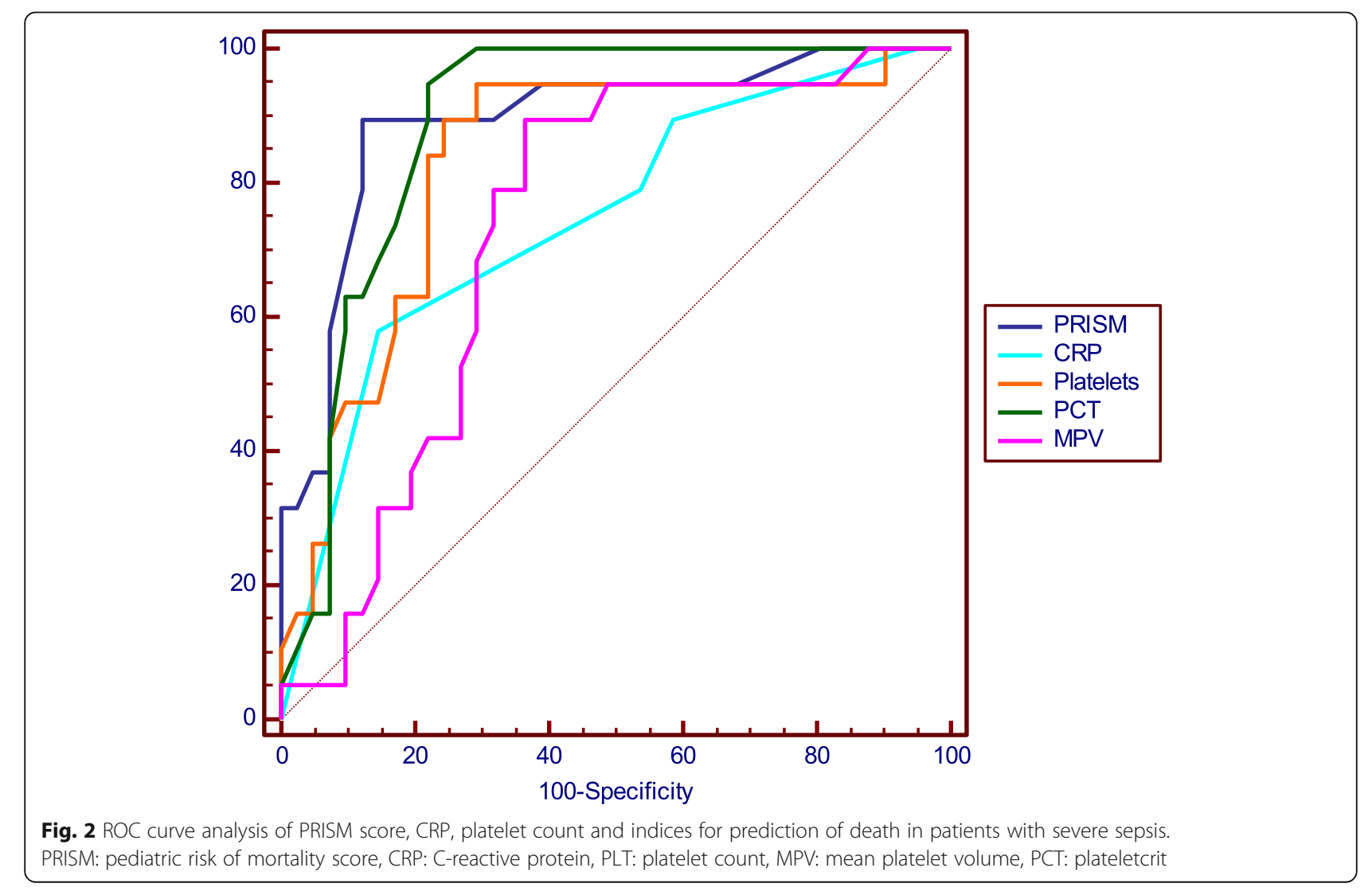


Table 7 Predictive values of ratios of platelet indices for mortality

\begin{tabular}{llllll}
\hline Variable & Optimal cutoff & AUC & Sensitivity (\%) & Specificity (\%) & Accuracy (\%) \\
\hline MPV/PLT & $\geq 0.076$ & 0.823 & $89.5 \%$ & $73.2 \%$ & $78.3 \%$ \\
MPV/PCT & $\geq 49.8$ & 0.882 & $94.7 \%$ & $78 \%$ & $83.3 \%$ \\
PDW/PLT & $\geq 0.14$ & 0.795 & $84.2 \%$ & $73.2 \%$ & $76.7 \%$ \\
PDW/PCT & $\geq 91.7$ & 0.841 & $84.2 \%$ & $75.6 \%$ & $78.3 \%$ \\
\hline
\end{tabular}

PLT platelet count, MPV mean platelet volume, PCT plateletcrit, PDW platelet distribution width, AUC Area under curve

number and size of platelet pseudopodia [30]. Platelet activation causes morphologic changes of platelets, including both spherical shape and pseudopodia formation. Platelets with increased number and size of pseudopodia differ in size, which affects PDW. In a previous study, PDW was significantly higher in patients with asserted platelet activation compared with healthy persons [31].

Platelet ratios calculated in this study, MPV/PLT, MPV/ PCT, PDW/PLT, PDW/PCT, were significantly higher in non-survivors than survivors. This is in accordance with a previous study in 2016 by Golwala et al., who found these ratios to be predictors of mortality in children [13].

PRISM score is a well-established score for prediction of mortality in pediatric patients. When we correlated the studied markers with PRISM score, PRISM score had significant negative associations with platelet count and plateletcrit, and it had a significant positive association with CRP level.

The negative associations of PRISM score with both platelet count and plateletcrit, confirm their negative prognostic values. Many studies addressed the relation of PRISM score and thrombocytopenia with the severity of sepsis. Gerardin et al., in 2018 found that thrombocytopenic patients had higher PRISM score at admission [32]. Yilmaz et al., in 2013 recommended that sequential platelet counting to identify risk as PRISM score [33].

Plateletcrit was the most sensitive parameter for predicting death, with thrombocytopenia taking second place by having the same sensitivity as the PRISM score. While MPV in this study was the least sensitive platelet parameter, but it was still more sensitive than CRP, which is the most commonly used inflammatory marker to be assessed

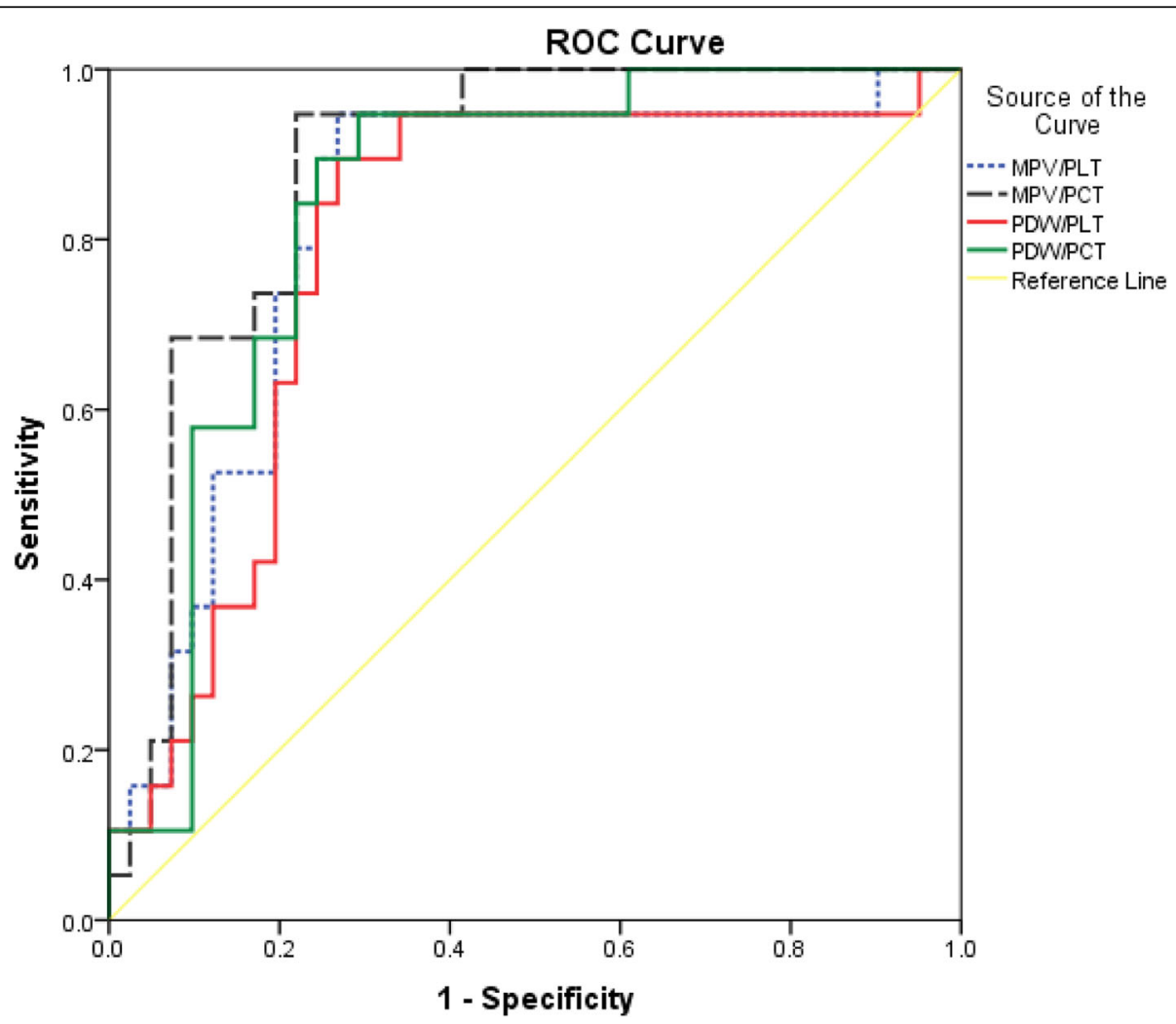

Fig. 3 ROC curve analysis of ratios of platelet indices for prediction of death in patients with severe sepsis 
in children with sepsis. Also, MPV/PCT ratio was the most sensitive ratio to predict mortality in this study.

\section{Limitations}

Our study has several limitations, for example, studies with larger sample size are needed. Moreover, further studies should address the changes occurring in platelet count and parameters during the course of pediatric sepsis by serial measurements of their levels during the course of the disease. Also, their association with longterm morbidity outcomes in children surviving severe sepsis syndrome should be elucidated.

\section{Conclusion}

Thrombocytopenia is an ominous sign that should be taken seriously in pediatric sepsis syndrome. Platelet indices and their ratios are readily available, sensitive, prognostic markers, that can identify the severe sepsis patients with poorest outcome. So, we recommend platelet count, platelet indices and their ratios, especially plateletcrit and MPV/PCT ratio, should be assessed in all sepsis patients upon admission to the PICU to guide the clinical decision along with the PRISM score and CRP.

\section{Abbreviations}

MPV: Mean platelet volume; PDW: Platelet distribution width; PCT: Plateletcrit; CRP: C-reactive protein; PICU: Pediatric intensive care unit; PRISM score: Pediatric risk of mortality score

\section{Acknowledgements}

Not applicable.

\section{Authors' contributions}

SZS, SOM and HMM participated in the design and planning of the study. HMM has done all the lab work. SOM and MMM participated in data collection, analysis of results and preparation of drafts of the manuscript. All authors read and approved the final manuscript.

\section{Funding}

No external funding.

\section{Availability of data and materials}

The datasets analyzed during the current study available from the corresponding author on reasonable request.

\section{Ethics approval and consent to participate}

The study was explained in details to the parents or legal guardians of the participant children and written consents were taken from them. The study was designed respecting the expected ethical aspects. It was performed according to the Declaration of Helsinki 1975, as revised in 2008 and approved by the Institutional Review Board and Medical Ethics Committee of Minia University.

\section{Consent for publication}

The authors hereby declare that the article is original and that its contents have not been published in full or in part. We also would like to declare that the manuscript has been read and approved by all authors.

\section{Competing interests}

All authors declare that they have no conflicts of interests.

\section{Author details}

${ }^{1}$ Pediatric Department, Children's University hospital, Faculty of Medicine, Minia University, El-Minya, Egypt. ${ }^{2}$ Clinical Pathology Department, Children's University hospital, Faculty of Medicine, Minia University, El-Minya, Egypt.

Received: 2 March 2020 Accepted: 6 August 2020

Published online: 19 August 2020

\section{References}

1. de Souza DC, Machado FR. Epidemiology of pediatric septic shock. J Pediatr Intensive Care. 2019;8(1):3-10. https://doi.org/10.1055/s-0038-1676634.

2. World Bank. World development report 1993 — investing in health: world development indicators. Oxford: Oxford University Press; 1993.

3. Murray CJ, Lopez AD. Measuring the global burden of disease. N Engl J Med. 2013;369:448-57.

4. Singer M, Deutschman CS, Seymour CW, Shankar-Hari M, Annane D, Bauer $M$, et al. The Third International Consensus Definitions for Sepsis and Septic Shock (Sepsis-3). JAMA. 2016;315(8):801-10.

5. Seymour CW, Liu VX, Iwashyna TJ, Brunkhorst FM, Rea TD, Scherag A, et al. Assessment of Clinical Criteria for Sepsis: For the Third International Consensus Definitions for Sepsis and Septic Shock (Sepsis-3). JAMA. 2016; 315(8):762-74.

6. Golebiewska EM, Poole AW. Platelet secretion: from haemostasis to wound healing and beyond. Blood Rev. 2015;29:153-62. https://doi.org/10.1016/j. blre.2014.10.003

7. Margetic S. Inflammation and haemostasis. Biochem Med (Zagreb). 2012;22: 49-62. https://doi.org/10.11613/BM.2012.006.

8. Mariani E, Filardo G, Canella V, Berlingeri A, Bielli A, Cattini L, et al. Plateletrich plasma affects bacterial growth in vitro. Cytotherapy. 2014;16:1294-304 https://doi.org/10.1016/j.jcyt.2014.06.003.

9. Frelinger AL 3rd, Torres AS, Caiafa A, Morton CA, Berny-Lang MA, Gerrits AJ, et al. Platelet-rich plasma stimulated by pulse electric fields: platelet activation, procoagulant markers, growth factor release and cell proliferation. Platelets. 2016;27(2):128-35.

10. Tuncel T, Ozgun A, Emirzeoglu L, Celik S, Bilgi O, Karagoz B. Mean platelet volume as a prognostic marker in metastatic colorectal cancer patients treated with bevacizumab-combined chemotherapy. Asian Pac J Cancer Prev. 2014;15(15):6421-3.

11. Chu SG, Becker RC, Berger PB, Bhatt DL, Eikelboom JW, Konkle B, et al. Mean platelet volume as a predictor of cardiovascular risk: a systematic review and meta-analysis. J Thromb Haemost. 2010;8(1):148-56.

12. Goldstein B, Giroir B, Randolph A. International consensus conference on pediatric Sepsis. International pediatric sepsis consensus conference: definitions for sepsis and organ dysfunction in pediatrics. Pediatr Crit Care Med. 2005:1:2-8.

13. Golwala ZM, Shah H, Gupta N, Sreenivas V, Puliyel JM. Mean platelet volume (MPV), platelet distribution width (PDW), platelet count and Plateletcrit (PCT) as predictors of in-hospital paediatric mortality: a case-control study. Afr Health Sci. 2016;16(2):356-62 https://doi.org/10.4314/ahs.v16i2.3.

14. Taniguchi T, Takagi D, Takeyama N, Kitazawa Y, Tanaka T. Platelet size and function in septic rats: changes in the adenylate pool. J Surg Res. 1990;49(5): 400-7.

15. Pollack MM, Patel KM, Ruttimann UE. PRISM III: An updated pediatric risk of mortality score. Crit Care Med. 1996:24:743-52.

16. Pollack MM, Holubkov R, Funai T, Berger JT, Clark AE, Meert K, et al. Simultaneous prediction of new morbidity, mortality, and survival without new morbidity from pediatric intensive care: a new paradigm for outcomes assessment. Crit Care Med. 2015;43:1699-709.

17. Manten Radovan I, Gutierrez Castrellon P, Zaldo Rodriguez R, Martinez NO PRISM score evaluation to predict outcome in pediatric patients on admission at an emergency department. Arch Med Res. 1996;27:553-8.

18. Verhoeven JJ, den Brinker M, Hokken-Koelega AC, Hazelzet JA, Joosten KF. Pathophysiological aspects of hyperglycemia in children with meningococcal sepsis and septic shock: a prospective, observational cohort study. Crit Care. 2011;15(1):R44. https://doi.org/10.1186/cc10006 Epub 2011 Jan 31.

19. Kaur G, Vinayak N, Mittal K, Kaushik JS, Aamir M. Clinical outcome and predictors of mortality in children with sepsis, severe sepsis, and septic shock from Rohtak, Haryana: a prospective observational study. Indian J Crit Care Med. 2014;18:437-41. 
20. Povoa P, Coelho L, Almeida E, Fernandes A, Mealha R, Moreira P, et al. Creactive protein as a marker of infection in critically ill patients. Clin Microbiol Infect. 2005;11:101-8.

21. Fan SL, Miller NS, Lee J, Remick DG. Diagnosing sepsis-the role of laboratory medicine. Clin Chim Acta. 2016;460:203-10.

22. Venkata C, Kashyap R, Farmer JC, Afessa B. Thrombocytopenia in adult patients with sepsis: incidence, risk factors, and its association with clinical outcome. J Intensive Care. 2013; (1):9. https://doi.org/10.1186/2052-0492-1-9 eCollection 2013.

23. Sah V, Giri A, KC M, Niraula N. Association of Thrombocytopenia and Mortality in critically ill children admitted to PICU in tertiary Hospital in Biratnagar. Birat J Health Sci. 2019;4(1):649-53.

24. Gao Y, Li Y, Yu X, Guo S, Ji X, Sun T, et al. The impact of various platelet indices as prognostic markers of septic shock. PLoS One. 2014;9(8):e103761. https://doi.org/10.1371/journal.pone.0103761.

25. Guclu E, Durmaz Y, Karabay O. Effect of severe sepsis on platelet count and their indices. Afr Health Sci. 2013;13(2):333-8.

26. Zampieri FG, Ranzani OT, Sabatoski V, de Souza HP, Barbeiro H, da Neto $L M C$, et al. An increase in mean platelet volume after admission is associated with higher mortality in critically ill patients. Ann Intensive Care. 2014;4(1):20. https://doi.org/10.1186/s13613-014-0020-1.

27. Kim CH, Kim SJ, Lee MJ, Kwon YE, Kim YL, Park KS, et al. An increase in mean platelet volume from baseline is associated with mortality in patients with severe sepsis or septic shock. PLoS One. 2015;10(3):e0119437.

28. Tajarernmuang P, Phrommintikul A, Limsukon A, Pothirat C, Chittawatanarat $K$. The role of mean platelet volume as a predictor of mortality in critically ill patients: a systematic review and meta-analysis. Crit Care Res Pract. 2016; 2016:4370834. https://doi.org/10.1371/journal.pone.0119437.

29. Sezgi C, Taylan M, Kaya H, Selimoglu Sen H, Abakay O, Demir M, et al. Alterations in platelet count and mean platelet volume as predictors of patient outcome in the respiratory intensive care unit. Clin Respir J. 2015; 9(4):403-8.

30. Vagdatli E, Gounari E, Lazaridou E, Katsibourlia E, Tsikopoulou F, Labrianou I. Platelet distribution width: a simple, practical and specific marker of activation of coaqulation. Hippokratia. 2010;14:28-32.

31. Tsompos C, Panoulis C, Toutouzas K, Zografos G, Papalois A. The acute effect of the antioxidant drug "U-74389g" on platelet distribution width during hypoxia Reoxygenation injury in rats. J Neurol Stroke. 2015;3(6): 00111.

32. Gerardin P, Ka AS, Imbert P. Thrombocytopenia as additional marker of severity in African children with plasmodium falciparum malaria. J Infect Dis Pathog. 2018;1:105.

33. Yilmaz S, Yildizdas D, Acipayam C, Bayram I, Ozcan N, Horoz OO. The effect of thrombocytopenia on outcome in critically ill children. Crit Care Shock. 2013;16(2):48-57.

\section{Publisher's Note}

Springer Nature remains neutral with regard to jurisdictional claims in published maps and institutional affiliations.

Ready to submit your research? Choose BMC and benefit from:

- fast, convenient online submission

- thorough peer review by experienced researchers in your field

- rapid publication on acceptance

- support for research data, including large and complex data types

- gold Open Access which fosters wider collaboration and increased citations

- maximum visibility for your research: over $100 \mathrm{M}$ website views per year

At $\mathrm{BMC}$, research is always in progress.

Learn more biomedcentral.com/submissions 